\title{
Awake supraglottic airway guided flexible bronchoscopic intubation in patients with anticipated difficult airways: a case series and narrative review
}

\author{
Wan Yen Lim and Patrick Wong \\ Department of Anesthesiology, Singapore General Hospital, Singapore, Singapore
}

\begin{abstract}
Awake intubation is indicated in difficult airways if attempts at securing the airway after induction of general anesthesia may lead to harm due to potential difficulties or failure in those attempts. Conventional awake flexible bronchoscopic intubation is performed via the nasal, or less commonly, oral route. Awake oral flexible bronchoscopic intubation (FBI) via a supraglottic airway device (SAD) is a less common technique; we refer to this as 'supraglottic airway guided' FBI (SAGFBI). We describe ten cases with anticipated difficult airways in which awake SAGFBI was performed. After sedation and adequate airway topicalization, an Ambu Auragain ${ }^{\text {TM }}$ SAD was inserted. A flexible bronchoscope, preloaded with a tracheal tube, was then inserted through the SAD. Finally, the tracheal tube was railroaded over the bronchoscope, through the SAD and into the trachea. The bronchoscope and the SAD were carefully removed, whilst keeping the tracheal tube in-situ. The technique was successful and well tolerated by all patients, and associated complications were rare. It also offered the advantages of performing an 'awake test insertion' of the SAD, an 'awake look' at the periglottic region, and an 'awake test ventilation. In certain patients, awake SAGFBI offers advantages over conventional awake FBI or awake videolaryngoscopy. More research is required to evaluate its success and failure rates, and identify associated complications. Its place in difficult airway algorithms may then be further established.
\end{abstract}

Keywords: Airway; Awake intubation; Fiberoptic intubation; Intratracheal; Intubation; Laryngoscopy; Ventilation; Videolaryngoscopy.

Corresponding author: Wan Yen Lim, M.Med (Anaes)

Department of Anaesthesiology, Singapore General Hospital, Outram Road, Singapore 169608, Singapore

Tel: +65-6321-4220, Fax: +65-6321-4220

Email: lim.wan.yen@singhealth.com.sg

ORCID: https://orcid.org/0000-0002-0335-0255

Received: July 22, 2019.

Revised: August 24, 2019.

Accepted: August 27, 2019.

Korean J Anesthesiol 2019 December 72(6): 548-557 https://doi.org/10.4097/kja.19318

\section{Introduction}

Awake intubation is indicated in a patient with a difficult airway if attempts at maintaining or securing the airway after induction of general anesthesia may encounter difficulties or result in failure, and lead to patient harm. Consideration should also be given to compounding factors, e.g., patients with severe airway obstruction, or those at risk of rapid desaturation or gastric aspiration. In rare cases, a post induction 'cannot intubate, cannot oxygenate' (CICO) scenario may develop, which is associated with severe morbidity and mortality, and the need for emergency front-of-neck access [1,2]. Indications for awake intubation include: anticipated or known difficult airway, cervical

(c) This is an open-access article distributed under the terms of the Creative Commons Attribution Non-Commercial License (http://creativecommons.org/ licenses/by-nc/4.0/), which permits unrestricted non-commercial use, distribution, and reproduction in any medium, provided the original work is properly cited. 
spine problems, space-occupying lesions in the mouth or neck, body mass index $(\mathrm{BMI})>35 \mathrm{~kg} / \mathrm{m}^{2}$, poor dental status, polyarthritis, avoidance of neuromuscular blocking drugs, induction in patients with increased cardiac risk, and for training purposes [3].

Awake intubation techniques include those using the flexible bronchoscope and, less widely, direct and video laryngoscopes [4] and rigid optical stylets [5]. The term 'flexible bronchoscopic intubation' (FBI) encompasses techniques using a flexible bronchoscope that transmit images either via fiberoptic bundles in its insertion cord ('fiberoptic bronchoscope') or via an integrated camera located at the tip of the cord ('video bronchoscope').

Conventional awake FBI has been described as the gold standard or technique of choice to secure the airway in certain groups of patients with predicted difficult airway [6,7]. It accounts for $<2 \%$ of all intubations [8], has a high success rate (98-99\%) [8,9], and low incidence of serious adverse events $(0.3 \%)$ [10]. It is performed via the nasal (75\% of cases) [8] or oral route. Awake oral intubation requires opening the upper airway to allow visualization of, and passage of the tracheal tube through, the glottis. This is achieved by patient effort, intubating aids (Berman or Ovassapian airway [11]), gentle tongue retraction or, as part of awake laryngoscopy, a gently applied laryngoscope blade. Awake oral FBI via the supraglottic airway is a less commonly known technique that uses a supraglottic airway device (SAD) to open up the upper airway; we refer to this as 'supraglottic airway guided' FBI (SAGFBI).

\section{Case Series}

Written patient consent was obtained from all patients. We describe ten cases with anticipated difficult airway in which awake SAGFBI was successfully performed, and discuss the technique's advantages and limitations.

All our patients had similar preparations for awake SAGFBI. The patients were pre-oxygenated via nasal prongs $(2-3 \mathrm{~L} /$ min oxygen) or via a Hudson face mask (10-15 L/min oxygen). Intravenous midazolam 1-2 mg was administered followed by upper airway topicalization with a $2 \%$ lignocaine gel gargle and $10 \%$ lignocaine spray to the back of the tongue. Intravenous remifentanil was administered using a target-controlled infusion with a starting effect-site concentration (Ce) of $0.5-1 \mathrm{ng} / \mathrm{ml}$ (depending on the patient's frailty) and then slowly titrated upwards to achieve light sedation (patient co-operative and tranquil). The Ambu Auragain ${ }^{\mathrm{TM}}$ SAD (Ambu A/S, Baltorpbakken, Ballerup; generally, size 3 for women and size 4 for men) was inserted and the cuff left deflated. This was to avoid apposition of the SAD cuff's inner borders leading to blocking of the view or the advancement of the bronchoscope. The patient was pre-oxygenated by connecting the SAD to the anesthetic circuit delivering
$100 \%$ oxygen. All of our cases demonstrated a normal capnograph waveform after SAD insertion. The anesthetic circuit was then disconnected and thin oxygen tubing was placed at the proximal end of the SAD's ventilation port to insufflate oxygen at $10-15 \mathrm{~L} / \mathrm{min}$. We then used the direct method of SAGFBI (the indirect method is described below) as follows. The flexible bronchoscope was pre-loaded with an appropriately sized tracheal tube and inserted into the SAD. The Auragain ${ }^{\mathrm{TM}}$ has the maximum tracheal tube size that it can accommodate printed on the proximal end of the ventilation port: size $3=6.5 \mathrm{~mm}$ and size $4=7.5 \mathrm{~mm}$. Once the bronchoscope exited the bowl of the SAD and closely approached the supraglottis, $2 \%$ lignocaine (4-8 ml) was gently injected via the working channel and onto the vocal cords and into the trachea. The tracheal tube was then railroaded over the bronchoscope and into the trachea. Finally, the bronchoscope was removed, leaving the tracheal tube in-situ. The cuff of the tracheal tube is then inflated and the tube secured to the patient. If required, the SAD was then removed independently of the tracheal tube by anchoring the latter within the trachea using a pair of Magill's forceps [12]. Other methods of anchoring (but not used by us) include placing the tip of a Fastrach $^{\mathrm{TM}}$ stabilizer rod or microlaryngeal tube at, and holding down, the proximal end of the tracheal tube.

\section{Case 1}

Our first case has been previously described [13]. He was a 42-year-old man, weighing $160 \mathrm{~kg}$, BMI $54 \mathrm{~kg} / \mathrm{m}^{2}$, scheduled for total thyroidectomy and bilateral neck dissection for metastatic papillary thyroid cancer with paratracheal lymph node and left recurrent laryngeal nerve involvement. His co-morbidities included asthma and hypertension. He had a Mallampati score of 3, large thick neck, and severe obstructive sleep apnea (OSA). Flexible nasendoscopy showed a narrow velopharynx and left vocal cord palsy. Due to his morbid obesity, predictors of difficult intubation, and difficult front-of-neck access, we secured his airway using awake SAGFBI.

\section{Case 2}

A 71-year-old man with a stage 3 vallecula squamous cell carcinoma was scheduled for a panendoscopy and biopsy of the base of the tongue. Airway examination was normal, but flexible nasendoscopy showed a left vocal cord palsy. MRI of the neck showed a 'lesion measuring $1.6 \mathrm{~cm}$ seen in the right vallecula extending to the floor of mouth.' To avoid laryngoscopy and traumatizing the vallecular lesion, we performed SAGFBI. 


\section{Case 3}

A 51-year-old woman was scheduled for an urgent corneal transplant in the evening. Her airway examination was normal. However, according to the eye surgeon, the patient had a previous failed intubation at their local eye hospital. However, we could not access the latter hospital's anesthetic records to corroborate this due to it being out of hours. She had a large right parotid tumor complicated by a facial nerve palsy. Due to the lack of previous airway documentation, we used SAGFBI for two purposes. First, it provided an 'awake look' to ensure there was no periglottic pathology causing the apparent previous failed intubation; none was seen. Second, it allowed an 'awake test ventilation' to indicate adequate positioning of, and to test the ability to ventilate via, the SAD.

\section{Case 4}

A 60-year-old man was scheduled for a deltopectoral flap to cover an exposed mandibular plate. He had a prior segmental mandibulectomy, fibula free flap reconstruction, and neck dissection for a left mandibular squamous cell carcinoma. The patient had also previously received radiotherapy treatment to the right neck for Hodgkin's lymphoma 30 years before. His airway assessment revealed mouth opening $<3 \mathrm{~cm}$, Mallampati score of 3 , thyromental distance $<6 \mathrm{~cm}$, and limited neck movement. We performed an 'awake test insertion' of the Auragain ${ }^{\mathrm{TM}}$ to ensure that the SAD could be inserted despite the decreased mouth opening; this was successful and we proceeded with SAGFBI.

\section{Case 5}

A 60-year-old man, weighing $89 \mathrm{~kg}$, was involved in a road traffic accident and became tetraplegic secondary to cervical cord injury. He had recently undergone posterior decompression laminectomy and fixation of his 1 st to 5 th cervical vertebrae. $\mathrm{He}$ now required a tracheostomy to facilitate tracheobronchial suctioning due to the presence of copious secretions despite chest physiotherapy. To avoid the risk of cervical movement associated with laryngoscopy [14-17], we performed awake SAGFBI with the neck stabilized with manual in-line stabilization and a neck collar.

\section{Case 6}

A 51-year-old man, weighing $99 \mathrm{~kg}$, BMI $33 \mathrm{~kg} / \mathrm{m}^{2}$, was scheduled for robotic assisted laparoscopic radical prostatectomy for prostate cancer. Airway assessment was normal. However, four months earlier, he had undergone a transperineal prostate biopsy under general anesthesia. At that time, after induction of anesthesia, face mask ventilation was difficult and required insertion of an oral airway and a two-person face mask ventilation technique. Two attempts at tracheal intubation using a CMAC ${ }^{\circledR}$ D-Blade ${ }^{\mathrm{TM}}$ failed due to difficulty directing the tracheal tube anteriorly towards the vocal cords. Rescue ventilation was then achieved after insertion of an Ambu Auragain ${ }^{\mathrm{TM}}$. SAGFBI was attempted at that time but the first attempt failed due to soft tissue obscuring the glottis. A second attempt was successful. For this admission, due to this history of failed intubation, we electively chose to perform awake SAGFBI.

\section{Case 7}

A 76-year-old man was scheduled for stereotactic biopsy of brain lesions. Five years previously, he had a radiological diagnosis of ankylosing spondylitis, i.e., paraspinal ossification ('bamboo spin'), and thoroughly fused sacroiliac joints. On this admission, a cervical spine X-ray showed squaring of the cervical vertebrae with ossification of the anterior and posterior longitudinal ligaments, consistent with ankylosing spondylitis. On examination, he had a fixed cervical spine with severely limited neck movement but his mouth opening was normal and had a Mallampati score of 2. Oral intubation was preferred due to the small risk of the patient needing postoperative ICU care; lung suctioning being easier via a larger oral tracheal tube than a narrower, curved nasal tube. Due to his anticipated difficult airway, preference for an oral intubation and to avoid manipulating his neck, we decided to perform awake SAGFBI.

\section{Case 8}

A 57-year-old man was scheduled for microlaryngoscopy and biopsy of a recurrent vocal cord tumor. He had previously undergone neck radiotherapy and had OSA. Airway examination found normal mouth opening, thyromental distance, and neck movement, and a Mallampati score of 4 . For his previous microlaryngoscopy, the anesthetist experienced both difficult face mask ventilation and difficult intubation. A Cormack-Lehane grade IV view was obtained using $\mathrm{McGrath}^{\mathrm{TM}}$ videolaryngoscopy (VL). For this admission, SAGFBI using a size 3 Auragain $^{\mathrm{TM}}$ was successful and a post intubation check direct laryngoscopy also revealed a Cormack-Lehane grade IV view.

\section{Case 9}

A 55-year-old woman was scheduled for endoscopic transnasal and transoral debridement of necrotic bone of the maxillary wall and hard palate (secondary to osteoradionecrosis). She had a history of nasopharyngeal cancer, and was treated with radiotherapy in 2008 and again in 2016 for cancer recurrence. She 
had undergone a nasopharyngectomy, neck dissection, and free flap reconstruction in 2017. Her comorbidities included panhypopituitarism and systemic lupus erythematosus. Her airway examination found an interdental distance of $1.6 \mathrm{~cm}$ and Mallampati score of 4 . We wanted to avoid nasal intubation as this would have limited surgical access to the nasal cavity.

\section{Case 10}

A 55-year-old man was scheduled for resection of a buccal tumor, neck dissection, and free flap reconstruction. On examination he had prominent upper incisors, an interdental distance of 1.5 fingerbreadths (approximately $2 \mathrm{~cm}$ ), and a Mallampati score of 4 . He had only stopped aspirin therapy the day before. To avoid the risk of epistaxis we decided to perform a trial of oral intubation via SAGFBI.

In both cases 9 and 10, we were unsure if a size 3 Auragain $^{\mathrm{TM}}$ would fit through such a small interdental gap; therefore, we planned an 'awake test insertion' of the Auragain ${ }^{\mathrm{TM}}$. If this failed in case 9, we would then attempt awake oral FBI by first placing the tracheal tube into the oropharynx to act as a conduit for FBI; in case 10, we would have converted to an awake nasal FBI. In both patients, a size 3 Auragain $^{\mathrm{TM}}$ was successfully inserted using gentle force. There was minimal gagging and both patients indicated that they were comfortable throughout, during both the SAD insertion and SAGFBI.

All patients tolerated SAGFBI well, with no coughing, and with either no gagging (most cases) or minimal gagging. Four patients had no, and three had minimal, recall of the procedure. Case 8 reported a mild sore throat (surgical procedure was microlaryngoscopy and vocal cord biopsy) on the next day follow-up. SAGFBI in cases 1 and 6 were performed by consultants; they had previously performed asleep SAGFBI twelve times (one of the authors, LWY) and once, respectively. The rest of the cases were performed by juniors with either 1-2 prior performances (cases 3, 5, 7, 8 and 9) or no prior experience (cases 2, 4, and 10) of asleep SAGFBI. Each awake SAGFBI was supervised by one author (PW), who has considerable experience in performing awake intubation.

\section{Discussion}

We described ten cases of awake SAGFBI. Each was performed successfully in patients with anticipated difficult airways, some by juniors with little or no prior experience with SAGFBI. We performed awake SAGFBI in our patients who had a history of difficult airway (cases 6 and 8) [18], when awake intubation was considered safer and/or advantageous, with predictors of difficult intubation, with trismus after successfully performing an 'awake test insertion' of an Auragain ${ }^{\mathrm{TM}}$ (cases 4, 9, and 10), when an 'awake look' $[19,20]$ was warranted (case 3 with an uncorroborated history of previous failed intubation), and when avoiding laryngoscopy was desired (case 2 with a vallecular lesion, and cases 5 and 7 with cervical pathology).

Difficult airway management requires a pre-formulated airway strategy; the foremost consideration is judging the clinical merits of awake versus asleep intubation [21]. The indications for awake intubation have been described above and include patients at risk of post induction CICO. The latter is rare (ranging from $1 / 3,000$ to $1 / 32,000$ [22-25]) but is associated with serious morbidity and mortality $[1,26,27]$. The 4 th National Audit Project (NAP 4) report described several cases of asleep (rather than awake) FBI in patients with anticipated difficult airway, which resulted in CICO scenarios requiring emergency front-of-neck access[1]. The report made the recommendation that 'when patient factors make fiberoptic intubation the preferred option in patients with head and neck pathology, consideration should first be made to performing it awake' [1].

\section{Awake intubation}

The advantages of an awake intubation arise from the patient not being exposed to induction agents and muscle relaxants, thus avoiding a post-induction CICO situation. Airway muscle tone and protective reflexes (including those against aspiration) are maintained, and spontaneous ventilation is preserved. $\mathrm{Pa}-$ tient hemodynamic stability is more likely. Neurological assessment can be made after awake intubation but before the induction of anesthesia; this will help determine if any neurological deterioration is attributable to the awake intubation. If the awake intubation technique fails, there is time to 'stop and think,' move onto the next airway plan, and seek assistance. Awake SAGFBI also allows confirmatory maneuvers to be performed before induction of anesthesia: 'awake test insertion,' 'awake look', and 'awake test ventilation' (discussed below).

For some patients, it is obvious when airway management is highly likely to be difficult or impossible and that awake intubation should be considered. These include those with previous difficult or failed intubation (cases 6 and 8) and significant head and neck abnormalities, e.g., trismus (cases 4, 9, and 10), fixed cervical spine (cases 5 and 7), previous surgery (cases 4 and 9), or thick or radiated front of neck (cases 1, 4, and 9). Other patients may have predictors of impossible mask ventilation [28] and/or difficult intubation $[18,29,30]$, such as obesity (case 1), large neck circumference in morbidly obese patients (case 1), OSA (cases 1 and 8), decreased mouth opening (cases 4, 9, and 10), high Mallampati grade (cases 4, 8, 9, and 10), decreased thyromental distance (case 4), limited neck movement (cases 4, 5 , and 7), and history of radiotherapy (cases 4, 8, and 9). However, standard bedside airway tests to predict difficult facemask 
ventilation, difficult laryngoscopy, difficult intubation, and failed intubation have poor sensitivities [31]. Difficult intubation therefore remains unexpected in $52-93 \%$ of cases [32,33]. In fact, cases 6 and 8 had a history of difficult or failed intubation but had a normal airway on clinical examination. On the other hand, one study showed that when difficult intubation was anticipated, only $25 \%$ had an actual difficult intubation [33].

An 'awake test insertion' of an SAD is beneficial in patients with trismus where oral intubation is preferred over the nasal route and when there is uncertainty as to whether the SAD will fit through the decreased interdental gap (cases 4, 9, and 10). Attempts at securing the airway after induction of general anesthesia in such patients may lead to CICO if insertion of, and subsequent ventilation via, oral airways and SADs fail. If SAD insertion is successful, then the advantages of an awake intubation (see above) and of using the SAD and SAGFBI remain. If it fails, then another airway plan can be implemented with the patients still awake and maintaining their own airway and ventilation. In cases 9 and 10, we performed awake test insertion using a size 3 Auragain $^{\mathrm{TM}}$ despite interdental distances of 1.6-2 $\mathrm{cm}$, albeit with gentle force to avoid trauma. The manufacturers state that the minimum interdental gap for this size SAD is 2.1 $\mathrm{cm}$ [34]. It should be noted that if the ventilation port is compressed by a narrow interdental gap, there may be resistance when railroading the tracheal tube over the bronchoscope and into the ventilation port. Using a narrow (e.g., 5.0 or $6.0 \mathrm{~mm}$ ) and well-lubricated microlaryngeal tube may help minimize this. The integrated bite block of the Auragain ${ }^{\mathrm{TM}}$ also prevents the patient biting on the bronchoscope. In case 9, alternative routes for awake intubation, i.e., nasal FBI or tracheostomy, were less preferred. Nasal FBI may have been difficult due to the distorted anatomy and necrotic bone, and a nasal tracheal tube would have hindered surgical access. Tracheostomy is invasive and is associated with serious complications [35]. In both cases 9 and 10, avoiding the nasal route for intubation eliminates the risk of severe epistaxis, which occurs in 1.3\% of nasal FBI [3].

An 'awake look, i.e., an examination of the upper airway before induction of anesthesia, is helpful for diagnostic purposes and to help predict difficult intubation $[19,20]$. This can be performed by using flexible nasendoscopy or as part of the initial laryngoscopic stages of awake intubation. If difficulty is predicted, then awake intubation should be considered. One study showed $100 \%$ sensitivity and $57 \%$ specificity for awake look direct laryngoscopy to diagnose difficult direct laryngoscopy after induction of anesthesia [20]. SAGFBI allows an initial awake look before proceeding with FBI (as per case 3, confirming no untoward periglottic pathology).

An 'awake test ventilation' has three functions. First, the presence of an adequate or normal capnograph waveform (seen in all our patients) indicates adequate SAD positioning. Second, it allows the anesthetist to test the ability to ventilate via the SAD. This is akin to the practice of testing face mask ventilation before administering muscle relaxants, but with the added advantage of testing SAD ventilation even before induction of anesthesia (so avoiding post-induction CICO). Third, it allows full pre-oxygenation and application of continuous positive pressure ventilation or pressure support ventilation. If the test fails, then the SAD should be removed and a different method to secure the airway considered.

The combination of an awake test insertion and awake test ventilation may be helpful. Case 4 had a mouth opening $<3$ $\mathrm{cm}$, but also all four risk factors predictive of difficult SAD ventilation: male sex (OR 1.75), age > 45 years (OR 1.70), short thyromental distance (OR 4.35), and limited neck movement (OR 2.75) [36]. Despite these, the awake test insertion and test ventilation were successful, and SAGFBI was easily performed.

\section{SAD use}

The role of the SAD is well established in airway management, acting either as a primary airway or, after a failed intubation, for rescue ventilation (plan B) [26,37]. Prompt instigation of plan $B$ rescue with an SAD minimizes task fixation, and avoids repeated attempts at intubation, which is associated with increased risk of morbidity and mortality $[1,38]$. SAD rescue ventilation is successful in $65-94 \%$ of cases $[39,40]$.

First generation SADs only have a ventilation port, whereas second generation SADs also have a gastric drainage tube to decrease the risk of aspiration [41]. Plan B with a second generation SAD (such as our institution's default SAD, the Ambu Auragain $^{\mathrm{TM}}$ ) is recommended for patients at risk of aspiration $[26,27,37]$. Second generation SADs have higher oro-pharyngeal leak pressures [41], typically up to $25-30 \mathrm{cmH}_{2} \mathrm{O}$, which allow higher ventilatory pressures to be used. Devices with high esophageal leak pressures may also protect against aspiration (i-gel $^{\circledR}, 13-21 \mathrm{cmH}_{2} \mathrm{O}$; classic laryngeal mask airway (LMA), $37-46 \mathrm{cmH}_{2} \mathrm{O}$; and ProSeal ${ }^{\mathrm{TM}} \mathrm{LMA}, 58-59 \mathrm{cmH}_{2} \mathrm{O}$ ) [42].

Correct positioning of the SAD is important to avoid leaks, obstruction, and poor glottic view during SAGFBI [43]. Correct positioning includes: 1) tip of the distal cuff in the esophagus, 2) epiglottis resting on the outside of the SAD cuff, 3) tip of the epiglottis aligned with the proximal cuff of the SAD, 4) cuff of the SAD adequately inflated to produce a seal, and 5) avoidance of cuff folding [43]. If SAD ventilation is then successful, four options are available to the anesthetist: proceed with surgery with the SAD, SAGFBI via the SAD, wake up the patient, and perform front-of-neck access [26]. 


\section{SAGFBI}

Awake intubation techniques require complex psychomotor skills and regular practice, and success and outcomes depend on the operator's experience [8]. However, first attempt success rates in patients with predicted difficult airways, even by experienced operators are low: for awake conventional FBI, 79-85\% $[3,7]$ and for awake VL, 54-71\% [7,44]. More than one attempt is often required for conventional awake FBI (27\% of successful attempts) [9]. Awake SAGFBI is therefore our proposed alternative. It has been termed 'low skill fiberoptic intubation,' but this is a misnomer as there are several steps involved and use of the bronchoscope is still required. The SAD has several functions that facilitate bronchoscopic intubation. First, it splints open the upper airway structures and pushes away secretions and blood that may cause FBI failure [1,9]. Second, the ventilation port is a conduit that guides the bronchoscope to the bowl exit of the SAD which sits closely to the glottis. Third, a full or partial view of the glottis is seen in a majority of the cases once the bronchoscope passes beyond the bowl. In normal airways, these views are obtained on the first attempt in asleep SAGFBI with the classic LMA [45], intubating LMA (ILMA) $[46,47]$, air-Q ${ }^{\circledR}[47,48]$, and ProSeal ${ }^{\mathrm{TM}}$ LMA [48], in 96\%, 66-90\%, 90-94\%, and $81 \%$ of cases, respectively. In predicted or known difficult airways, these views are obtained with the i-gel ${ }^{\circledR}$ [49], ILMA [49], LMA Supreme [50], and i-gel ${ }^{\circledR}$ [50] in $78 \%, 77 \%, 84 \%$, and $82 \%$ of the cases, respectively. Collectively, these functions decrease the need to identify or navigate around the upper airway anatomy and results in the high success rates of asleep SAGFBI. These may explain why SAGFBI may be successful after failed or difficult asleep VL (cases 6 and 8, respectively) or after failed awake conventional FBI [51].

If a glottic view is not initially seen during SAGFBI, this may be because of SAD malpositioning; the epiglottis is deflected and in a suboptimal position in $50-80 \%$ of SAD insertions [52]. Malpositioning can be minimized by: avoiding SAD cuff hyperinflation (dislocation of SAD); cuff hypoinflation, which also increases the risk for aspiration; use of a too deep or too small SAD; and use of a too superficial or too large SAD [43]. Options to remedy malposition include a jaw thrust to open the oropharyngeal space, use of a railroading technique with the help of a bougie or orogastric tube, and inserting the SAD under vision using a VL $[43,52]$. In our experiences with SAGFBI (including outside of this case series), using a jaw thrust, pulling the SAD out by approximately $<1 \mathrm{~cm}$, or deflating the SAD cuff improves a suboptimal glottic view in most cases. In case 6 , soft tissue obscured the glottic view in a previously performed (asleep) SAGFBI but was successful on the second attempt; however, there was no record of which remedial maneuver was used.

First attempt asleep SAGFBI success rates in patients with normal airways for various SADs are $98 \%$ with an air- $Q^{\circledR}$ [47], 90-95\% with an ILMA [46,47,53,54], 81\% with a classic LMA $81 \%$ [45], and $100 \%$ with an i-gel ${ }^{\circledR}$ [54]. In patients with predicted or actual difficult airways, first time success rates are $96 \%$ with an i-gel ${ }^{\circledR}[49]$ and $97 \%$ with an air- $Q^{\circledR}[55]$. Moreover, novices have been successful with the technique in patients with normal and difficult airways $[45,56]$. One study showed no significant differences between trainees and experts in SAGFBI timings and number of attempts [45]. Novices also performed SAGFBI in our case series (cases 2, 4, and 10).

Using an SAD to splint open the oropharynx has advantages over the Berman airway. Unlike the latter, most SADs are cuffed devices. When the cuff is inflated and the SAD is connected to an anesthetic circuit, it allows spontaneous or controlled ventilation, and allows for the delivery of $100 \%$ oxygen for full pre-oxygenation before attempting SAGFBI. The gastric drainage tube of second generation SADs decreases the risk of aspiration of gastric contents. The bowl sits close to the glottis so that the vocal cords are seen in 66-96\% of the cases (see above). One study showed complete or partial obstructed views of the glottis using the Berman airway for bronchoscope advancement in $23 \%$ and $20 \%$ of the cases, respectively [11].

Maintaining oxygenation during airway manipulation is important. During SAGFBI, we insufflate oxygen via oxygen tubing placed at the mouth of the ventilation port. Nasal oxygen supplementation, which can be administered during awake conventional FBI or VL, cannot be performed as the SAD blocks the nasal passage distally.

SAGFBI can be performed using either the direct or indirect method [57]. In our case series, we only used the direct method (see above). The indirect method uses a bronchoscope preloaded with an Aintree Intubating Catheter (AIC, Cook UK, Letchworth, UK). Both are inserted through the SAD and into the trachea. The bronchoscope and SAD are then removed whilst keeping the AIC within the trachea, and only then is a tracheal tube railroaded over the AIC. This method is more complex, takes longer to perform and, when transitioning between the various steps involved, airway control and the ability to conventionally ventilate the patient are lost [57].

We used the Ambu Auragain ${ }^{\mathrm{TM}}$ as it is specifically designed for direct SAGFBI unlike, for example, the ProSeal ${ }^{\mathrm{TM}}$ LMA. This can be explained by comparing the characteristics of size 4 devices. The internal diameters of the ventilation port of the Auragain $^{\mathrm{TM}}$ and ProSeal ${ }^{\mathrm{TM}}$ are $12 \mathrm{~mm}$ and $9 \mathrm{~mm}$, respectively. The Auragain $^{\mathrm{TM}}$ allows for insertion of a $7.5 \mathrm{~mm}$ tracheal tube for direct SAGFBI. The ProSeal ${ }^{\mathrm{TM}}$ prevents insertion of a size $5.0 \mathrm{~mm}$ microlaryngeal tube, and thus, indirect SAGFBI has to be used. The Auragain ${ }^{\mathrm{TM}}$ ventilation port is also shorter than the ProSeal ${ }^{\mathrm{TM}}$ LMA $(15.6 \mathrm{~cm}$ vs. $17.3 \mathrm{~cm}$, respectively) and so allows deeper insertion of the tracheal tube. This prevents the inflated 
tracheal tube cuff being at the level of the vocal cords leading to a cuff leak. It has an integrated bite block to prevent biting on the bronchoscope and has a navigation mark (a black circle on the inner, posterior aspect of the ventilation port proximal to the bowl) to guide the bronchoscope. In addition, it has a mean oropharyngeal leak pressure of $30 \mathrm{cmH}_{2} \mathrm{O}$ [58].

\section{SAGFBI in the sitting up position}

We performed all our awake SAGFBI with the patient in the sitting position and with the operator standing face-to-face with the patient. An awake patient in the sitting position provides the added advantages of gravity helping maintain airway patency and lung functional residual capacity which increases safe apnea time [59]; maintaining the stomach lower than the glottis, potentially decreasing the risk of aspiration; allowing treatment of some patients who are unable to lie flat, such as those with orthopnea, severe cervical spine disease (e.g., case 7 with ankylosing spondylitis), or immobilized in a halo traction; and being less distressing as patients can sit up and look at the operator whilst an awake intubation is performed. Direct laryngoscopy or VL is difficult or impossible in a fully sitting patient. Case 1 was morbidly obese and thus, awake intubation in the sitting position was considered beneficial [59]. Various authors include obesity, e.g., BMI $>35 \mathrm{~kg} / \mathrm{m}^{2}$, as an indication for awake conventional FBI $[3,24]$ or awake SAGFBI $[13,60,61]$.

\section{Patient tolerance}

All our patients tolerated the technique well after adequate sedation and upper airway topicalization, with little or no gagging. Five patients had no recall and this is likely due to the midazolam administered beforehand. Awake Ambu Auragain ${ }^{\mathrm{TM}}$ insertion may be better tolerated and less traumatic than awake laryngoscopy for various reasons. First, the Ambu Auragain ${ }^{\mathrm{TM}}$ is made of soft polyvinyl chloride, in contrast to hard, rigid laryngoscope blades. VL and use of a rigid stylet is associated with oropharyngeal trauma [62] and gagging [44]. Even conventional awake FBI has a high incidence of gagging (23\% of successful attempts) [9]. Second, the tip of the SAD lies in the upper esophageal sphincter whereas a laryngoscope blade tip is usually inserted into the vallecula, which may theoretically elicit the gag reflex to a greater extent [7]. Avoiding instrumentation of the vallecula is also important if there are lesions at risk of trauma (e.g., case 2). Third, no laryngoscopic force is required to visualize the glottis as a full or partial view of the vocal cords is readily seen in most cases (see above) when the bronchoscope exits the bowl of the SAD. Avoiding laryngoscopic force is desirable in patients with cervical pathology (e.g., cases 5 and 7). Moore et al. [44] performed awake VL in morbidly obese patients, which had success on the 1st, 2nd, and 3rd attempt in 54\%, 30\%, and $12 \%$ of cases, respectively. Failures occurred in two (4\%) patients and were associated with severe gagging.

In case 5 , the patient's cervical spine was recently stabilized by surgical fixation so we deemed it safe to proceed with SAGFBI. However, it is prudent to understand the effects of SAD insertion and SAGFBI on the cervical spine. In patients with normal cervical spines, intubation with the ILMA causes less cervical spine motion than using Macintosh direct laryngoscopy $[14,15]$, but more than during nasal FBI [16]. However, in patients with an unstable cervical spine, precautions must be taken during airway manipulation to minimize cervical spine movement and cervical pressure. One study used human cadavers with a posteriorly destabilized third cervical (C-3) vertebra [17]. Classic LMA insertion and ILMA ${ }^{\mathrm{TM}}$ insertion/intubation produced more C2-3 displacement and motion than nasal FBI, but less than face mask ventilation with chin lift/jaw thrust and direct laryngoscopic intubation [17]. Cervical pressure is another important consideration. One cadaver study showed that classic LMA and ILMA ${ }^{\mathrm{TM}}$ insertion resulted in high maximal cervical pressures (224 and $273 \mathrm{cmH}_{2} \mathrm{O}$, respectively) [63]. This compared to low or zero pressures during intubation using a laryngoscope or oral FBI since little or no contact was made with the anterior body of C2-3. Despite these concerns, SAGFBI via the ILMA ${ }^{\mathrm{TM}}$ has been used in patients with cervical spine instability with no reported adverse sequelae [64].

\section{Limitations of SAGFBI}

SAGFBI shares some of the same complications and causes of failure as conventional awake FBI [65]. It is also performed via the oral route and a different technique is required if nasal intubation is indicated. In patients with restricted mouth opening, SAD insertion may not be possible. However, in one of our patients it was successful despite an interdental gap of $1.6 \mathrm{~cm}$. The size of tracheal tube for SAGFBI is limited by the diameter of the SAD ventilation port. Using a narrow tracheal tube may increase airflow resistance and airway pressures. There may also be a need to exchange for a larger tracheal tube if lung suction is required in cases of postoperative intensive care management.

\section{Conclusions}

SAGFBI as a useful rescue technique with a high success rate after a failed intubation. Awake SAGFBI offers certain advantages over conventional awake FBI or awake VL. It also allows for various confirmatory maneuvers (i.e., awake test insertion, awake look, and awake test ventilation) before induction of anesthesia and thus avoids the risk of post-induction CICO. More research is required on awake SAGFBI to evaluate its success 
and failure rates, and determine what complications may arise. Its place in difficult airway algorithms may then be established.

\section{Acknowledgments}

PW has received airway equipment for evaluation and research from numerous companies, and has lectured at conferences and symposiums sponsored by Ambu. He has no financial interest in any airway company.

\section{Conflicts of Interest}

No potential conflict of interest relevant to this article was reported.

\section{Author Contributions}

Wan Yen Lim (Data curation; Writing-original draft)

Patrick Wong (Conceptualization; Data curation; Supervision; Writing-review \& editing)

\section{ORCID}

Wan Yen Lim, https://orcid.org/0000-0002-0335-0255

Patrick Wong, https://orcid.org/0000-0002-3212-9496

\section{References}

1. Cook T, Woodall N, Frerk C. 4th National Audit Project of The Royal College of Anaesthetists and The Difficult Airway Society: Major complications of airway management in the United Kingdom. London: The Royal College of Anaesthetists; 2011 Mar. Available from https://www.rcoa.ac.uk/system/files/CSQ-NAP4-Full.pdf

2. Cook TM, Woodall N, Frerk C. Major complications of airway management in the UK: results of the Fourth National Audit Project of the Royal College of Anaesthetists and the Difficult Airway Society. Part 1: anaesthesia. Br J Anaesth 2011; 106: 617-31.

3. Heidegger T, Gerig HJ, Ulrich B, Schnider TW. Structure and process quality illustrated by fibreoptic intubation: analysis of 1612 cases. Anaesthesia 2003; 58: 734-9.

4. Alhomary M, Ramadan E, Curran E, Walsh SR. Videolaryngoscopy vs. fibreoptic bronchoscopy for awake tracheal intubation: a systematic review and meta-analysis. Anaesthesia 2018; 73: 1151-61.

5. Abramson SI, Holmes AA, Hagberg CA. Awake insertion of the Bonfils Retromolar Intubation Fiberscope in five patients with anticipated difficult airways. Anesth Analg 2008; 106: 1215-7.

6. Wilson WM, Smith AF. The emerging role of awake videolaryngoscopy in airway management. Anaesthesia 2018; 73: 1058-61.

7. Rosenstock CV, Thøgersen B, Afshari A, Christensen AL, Eriksen C, Gätke MR. Awake fiberoptic or awake video laryngoscopic tracheal intubation in patients with anticipated difficult airway management: a randomized clinical trial. Anesthesiology 2012; 116: 1210-6.

8. El-Boghdadly K, Onwochei DN, Cuddihy J, Ahmad I. A prospective cohort study of awake fibreoptic intubation practice at a tertiary centre. Anaesthesia 2017; 72: 694-703.

9. Law JA, Morris IR, Brousseau PA, de la Ronde S, Milne AD. The incidence, success rate, and complications of awake tracheal intubation in 1,554 patients over 12 years: an historical cohort study. Can J Anaesth 2015; 62: 736-44.

10. Cabrini L, Baiardo Redaelli M, Ball L, Filippini M, Fominskiy E, Pintaudi M, et al. Awake Fiberoptic Intubation Protocols in the Operating Room for Anticipated Difficult Airway: A Systematic Review and Meta-analysis of Randomized Controlled Trials. Anesth Analg 2019; 128: 971-80.

11. Greenland KB, Ha ID, Irwin MG. Comparison of the Berman Intubating Airway and the Williams Airway Intubator for fibreoptic orotracheal intubation in anaesthetised patients. Anaesthesia 2006; 61: 678-84.

12. Tan DJ, Tan LZ, Seet E. Low-skill flexible bronchoscopic intubation - Overcoming common pitfalls. J Clin Anesth 2017; 38: 83-4.

13. Lim WY, Teo CE, Wong P. Awake intubation via an ambu auragain in a patient with extreme obesity: a case report. A A Pract 2019; 13: 4850.

14. Wahlen BM, Gercek E. Three-dimensional cervical spine movement during intubation using the Macintosh and Bullard laryngoscopes, the bonfils fibrescope and the intubating laryngeal mask airway. Eur J Anaesthesiol 2004; 21: 907-13.

15. Waltl B, Melischek M, Schuschnig C, Kabon B, Erlacher W, Nasel C, et al. Tracheal intubation and cervical spine excursion: direct laryngoscopy vs. intubating laryngeal mask. Anaesthesia 2001; 56: 221-6.

16. Sahin A, Salman MA, Erden IA, Aypar U. Upper cervical vertebrae movement during intubating laryngeal mask, fibreoptic and direct laryngoscopy: a video-fluoroscopic study. Eur J Anaesthesiol 2004; 21: 819-23.

17. Brimacombe J, Keller C, Künzel KH, Gaber O, Boehler M, Pühringer F. Cervical spine motion during airway management: a cinefluoroscopic study of the posteriorly destabilized third cervical vertebrae in human cadavers. Anesth Analg 2000; 91: 1274-8.

18. Arné J, Descoins P, Fusciardi J, Ingrand P, Ferrier B, Boudigues D, et al. Preoperative assessment for difficult intubation in general and ENT surgery: predictive value of a clinical multivariate risk index. Br J Anaesth 1998; 80: 140-6.

19. Jones PM, Harle CC. Avoiding awake intubation by performing awake GlideScope laryngoscopy in the preoperative holding area. Can J 
Anaesth 2006; 53: 1264-5.

20. Gupta S, Macneil R, Bryson G. Laryngoscopy in conscious patients with remifentanil: how useful is an "awake look"? J Clin Anesth 2012; 24: $19-24$.

21. Apfelbaum JL, Hagberg CA, Caplan RA, Blitt CD, Connis RT, Nickinovich DG, et al. Practice guidelines for management of the difficult airway: an updated report by the American Society of Anesthesiologists Task Force on Management of the Difficult Airway. Anesthesiology 2013; 118: 251-70.

22. Huitink JM, Lie PP, Heideman I, Jansma EP, Greif R, van Schagen N, et al. A prospective, cohort evaluation of major and minor airway management complications during routine anaesthetic care at an academic medical centre. Anaesthesia 2017; 72: 42-8.

23. Nagaro T, Yorozuya T, Sotani M, Adachi N, Tabo E, Arai T, et al. Survey of patients whose lungs could not be ventilated and whose trachea could not be intubated in university hospitals in Japan. J Anesth 2003; 17: 232-40.

24. Heidegger T, Gerig HJ, Ulrich B, Kreienbühl G. Validation of a simple algorithm for tracheal intubation: daily practice is the key to success in emergencies--an analysis of 13,248 intubations. Anesth Analg 2001; 92: 517-22.

25. Tachibana N, Niiyama Y, Yamakage M. Incidence of cannot intubate-cannot ventilate (CICV): results of a 3-year retrospective multicenter clinical study in a network of university hospitals. J Anesth 2015; 29: 326-30.

26. Frerk C, Mitchell VS, McNarry AF, Mendonca C, Bhagrath R, Patel A, et al. Difficult Airway Society 2015 guidelines for management of unanticipated difficult intubation in adults. Br J Anaesth 2015; 115: 827-48.

27. Higgs A, McGrath BA, Goddard C, Rangasami J, Suntharalingam G, Gale R, et al. Guidelines for the management of tracheal intubation in critically ill adults. Br J Anaesth 2018; 120: 323-52.

28. Kheterpal S, Martin L, Shanks AM, Tremper KK. Prediction and outcomes of impossible mask ventilation: a review of 50,000 anesthetics. Anesthesiology 2009; 110: 891-7.

29. Leong SM, Tiwari A, Chung F, Wong DT. Obstructive sleep apnea as a risk factor associated with difficult airway management - A narrative review. J Clin Anesth 2018; 45: 63-8.

30. Riad W, Vaez MN, Raveendran R, Tam AD, Quereshy FA, Chung F, et al. Neck circumference as a predictor of difficult intubation and difficult mask ventilation in morbidly obese patients: A prospective observational study. Eur J Anaesthesiol 2016; 33: $244-9$.

31. Roth D, Pace NL, Lee A, Hovhannisyan K, Warenits AM, Arrich J, et al. Bedside tests for predicting difficult airways: an abridged Cochrane diagnostic test accuracy systematic review. Anaesthesia 2019; 74: 915-28.

32. Paix AD, Williamson JA, Runciman WB. Crisis management during anaesthesia: difficult intubation. Qual Saf Health Care 2005 ; 14 : e5.

33. Nørskov AK, Rosenstock CV, Wetterslev J, Astrup G, Afshari A, Lundstrøm LH. Diagnostic accuracy of anaesthesiologists' prediction of difficult airway management in daily clinical practice: a cohort study of 188064 patients registered in the Danish Anaesthesia Database. Anaesthesia 2015; 70: 272-81.

34. Ambu ${ }^{\circledR}$ AuraGain $^{\text {TM }}$ [Internet]. Ballerup: Ambu A/S. 2015 [cited 2019 Jul 22]. Available from http://ambu.com.br/Admin/Public/ DWSDownload.aspx?File=\%2FFiles\%2FFiler\%2Fbrazil\%2FDatasheets\%2FIE_AuraGain_493970001_V04_0815.pdf

35. Halum SL, Ting JY, Plowman EK, Belafsky PC, Harbarger CF, Postma GN, et al. A multi-institutional analysis of tracheotomy complications. Laryngoscope 2012; 122: 38-45.

36. Saito T, Chew ST, Liu WL, Thinn KK, Asai T, Ti LK. A proposal for a new scoring system to predict difficult ventilation through a supraglottic airway. Br J Anaesth 2016; 117 Suppl 1: i83-6.

37. Mushambi MC, Kinsella SM, Popat M, Swales H, Ramaswamy KK, Winton AL, et al. Obstetric Anaesthetists' Association and Difficult Airway Society guidelines for the management of difficult and failed tracheal intubation in obstetrics. Anaesthesia 2015; 70: $1286-306$.

38. Mort TC. Emergency tracheal intubation: complications associated with repeated laryngoscopic attempts. Anesth Analg 2004; 99: 607-13.

39. Thomsen JLD, Nørskov AK, Rosenstock CV. Supraglottic airway devices in difficult airway management: a retrospective cohort study of 658,104 general anaesthetics registered in the Danish Anaesthesia Database. Anaesthesia 2019; 74: 151-7.

40. Parmet JL, Colonna-Romano P, Horrow JC, Miller F, Gonzales J, Rosenberg H. The laryngeal mask airway reliably provides rescue ventilation in cases of unanticipated difficult tracheal intubation along with difficult mask ventilation. Anesth Analg 1998; 87: 661-5.

41. Timmermann A. Supraglottic airways in difficult airway management: successes, failures, use and misuse. Anaesthesia 2011; 66 Suppl 2: 4556.

42. Schmidbauer W, Bercker S, Volk T, Bogusch G, Mager G, Kerner T. Oesophageal seal of the novel supralaryngeal airway device I-Gel in comparison with the laryngeal mask airways Classic and ProSeal using a cadaver model. Br J Anaesth 2009; 102: 135-9.

43. Van Zundert AA, Kumar CM, Van Zundert TC. Malpositioning of supraglottic airway devices: preventive and corrective strategies. Br J Anaesth 2016; 116: 579-82.

44. Moore AR, Schricker T, Court O. Awake videolaryngoscopy-assisted tracheal intubation of the morbidly obese. Anaesthesia 2012; 67: 2325.

45. Hodzovic I, Janakiraman C, Sudhir G, Goodwin N, Wilkes AR, Latto IP. Fibreoptic intubation through the laryngeal mask airway: effect of operator experience*. Anaesthesia 2009; 64: 1066-71.

46. Keller C, Brimacombe J. The intubating laryngeal mask airway in fresh cadavers vs. paralysed anesthetised patients. Can J Anaesth 1999; 46: 1067-9.

47. Abdel-Halim TM, Abo El Enin MA, Elgoushi MM, Afifi MG, Atwa HS. Comparative study between Air-Q and Intubating Laryngeal Mask 
Airway when used as conduit for fiber-optic. Egypt J Anaesth 2014; 30: 107-13.

48. Galgon RE, Schroeder KM, Han S, Andrei A, Joffe AM. The air-Q $\left({ }^{\circledR}\right)$ intubating laryngeal airway vs the LMA-ProSeal ${ }^{\mathrm{TM}}$ : a prospective, randomised trial of airway seal pressure. Anaesthesia 2011; 66: 1093-100.

49. Kleine-Brueggeney M, Theiler L, Urwyler N, Vogt A, Greif R. Randomized trial comparing the i-gel ${ }^{\mathrm{TM}}$ and Magill tracheal tube with the single-use ILMA ${ }^{\mathrm{TM}}$ and ILMA ${ }^{\mathrm{TM}}$ tracheal tube for fibreoptic-guided intubation in anaesthetized patients with a predicted difficult airway. Br J Anaesth 2011; 107: 251-7.

50. Theiler LG, Kleine-Brueggeney M, Kaiser D, Urwyler N, Luyet C, Vogt A, et al. Crossover Comparison of the Laryngeal Mask Supreme ${ }^{\mathrm{TM}}$ and the i-gel ${ }^{\mathrm{TM}}$ in Simulated Difficult Airway Scenario in Anesthetized Patients. Anesthesiology 2009; 111: 55-62.

51. Moon HS, Lee JY, Chon JY, Lee H, Kim D. Air- $\mathrm{Q}^{\circledR}$ sp-assisted awake fiberoptic bronchoscopic intubation in a patient with Ludwig's angina. Korean J Anesthesiol 2014; 67(Suppl): S23-4.

52. Van Zundert AAJ, Gatt SP, Kumar CM, Van Zundert TCRV, Pandit JJ. 'Failed supraglottic airway': an algorithm for suboptimally placed supraglottic airway devices based on videolaryngoscopy. Br J Anaesth 2017; 118: 645-9.

53. Joo HS, Rose DK. The intubating laryngeal mask airway with and without fiberoptic guidance. Anesth Analg 1999; 88: 662-6.

54. Moore A, Gregoire-Bertrand F, Massicotte N, Gauthier A, Lallo A, Ruel M, et al. I-gel versus LMA-fastrach supraglottic airway for flexible bronchoscope-guided tracheal intubation using a parker (GlideRite) endotracheal tube: a randomized controlled trial. Anesth Analg 2015; 121: 430-6.

55. Samir EM, Sakr SA. The air-Q as a conduit for fiberoptic aided tracheal intubation in adult patients undergoing cervical spine fixation: a prospective randomized study. Egypt J Anaesth 2012; 28: 133-7.

56. Higgs A, Clark E, Premraj K. Low-skill fibreoptic intubation: use of the Aintree Catheter with the classic LMA. Anaesthesia 2005; 60: 915 20.

57. Chow SY, Tan YR, Wong TG, Ho VK, Matthews AM, Li HH, et al. Direct and indirect low skill fibre-optic intubation: a randomised crossover manikin study of six supraglottic airway devices. Indian J Anaesth 2018; 62: 350-8.

58. Moser B, Audigé L, Keller C, Brimacombe J, Gasteiger L, Bruppacher HR. A prospective, randomized trial of the Ambu AuraGain ${ }^{\mathrm{TM}}$ laryngeal mask versus the LMA ${ }^{\circledR}$ protector airway in paralyzed, anesthetized adult men. Minerva Anestesiol 2018; 84: 684-92.

59. Ibañez J, Raurich JM. Normal values of functional residual capacity in the sitting and supine positions. Intensive Care Med 1982; 8: 173-7.

60. Wender R, Goldman AJ. Awake insertion of the fibreoptic intubating LMA CTrach in three morbidly obese patients with potentially difficult airways. Anaesthesia 2007; 62: 948-51.

61. Shiraishi $\mathrm{T}$. Awake insertion of the air- $\mathrm{Q}^{\mathrm{TM}}$ intubating laryngeal airway device that facilitates safer tracheal intubation in morbidly obese patients. Br J Anaesth 2013; 111: 1024-5.

62. Aziz MF, Healy D, Kheterpal S, Fu RF, Dillman D, Brambrink AM. Routine clinical practice effectiveness of the Glidescope in difficult airway management: an analysis of 2,004 Glidescope intubations, complications, and failures from two institutions. Anesthesiology 2011; 114: 34-41.

63. Keller C, Brimacombe J, Keller K. Pressures exerted against the cervical vertebrae by the standard and intubating laryngeal mask airways: a randomized, controlled, cross-over study in fresh cadavers. Anesth Analg 1999; 89: 1296-300.

64. Jadhav T, Sriganesh K, Reddy M, Chakrabarti D. Comparative study of fiberoptic guided versus intubating laryngeal mask airway assisted awake orotracheal intubation in patients with unstable cervical spine. Minerva Anestesiol 2017; 83: 804-11.

65. Asai T, Shingu K. Difficulty in advancing a tracheal tube over a fibreoptic bronchoscope: incidence, causes and solutions. Br J Anaesth 2004; 92: 870-81. 